http://sciforum.net/conference/ece-1

Conference Proceedings Paper - Energies ,, Whither Energy Conversion? Present Trends, Current Problems and Realistic Future Solutions"

\title{
State of the Art and Future Trends in Grid Codes Applicable to Isolated Electrical Systems
}

\section{Julia Merino $^{1, *}$ and Carlos Veganzones ${ }^{1}$}

1 Department of Electrical Engineering, ETS Ingenieros Industriales, Technical University of Madrid, C/Jose Gutierrez Abascal 2, Madrid 28006, Spain; E-Mails: julia.merino@upm.es (J.M.); carlos.veganzones@upm.es (C.V.)

* Author to whom correspondence should be addressed; E-Mail: julia.merino@upm.es (J.M.); Tel.: +34-91-336-3025; Fax: +34-91-336-3008.

Received: 5 November 2013 / Accepted: 23 February 2014 / Published: 14 March 2014

\begin{abstract}
The isolated electrical systems lack electrical interconnection to other networks and they are usually placed in geographically isolated areas -mainly islands or locations in developing countries-. Until recently, only the diesel generators were able to assure a safe and reliable supply in exchange for very high prices in fuel transport and in system operation. System operators (DSOs) are increasingly seeking to replace traditional energy models based on large groups of conventional generation by mixed solutions where diesel groups are held as backup generation and important advantages are provided by renewable energy sources. The grid codes determine the technical requirements to be fulfilled for the generators connected in any electrical network but regulations applied to isolated grids are more demanding. In technical literature it is rather easy to find and compare grid codes for interconnected electrical systems. However, the existing literature is incomplete and sparse regarding weak grids. This paper aims to review the current state of isolated systems and grid codes applicable to them, setting the comparison and defining the guidelines predictably followed by the upcoming regulations.
\end{abstract}

Keywords: grid codes; isolated electrical grid; grid disturbances. 


\section{Introduction}

According to the European Directive 2009/72/EC, a small isolated system is defined as a system that consumed less than $3000 \mathrm{GWh}$ in 1996 and which received less than 5\% of this energy through interconnections [1]. The isolated systems are usually found in remote or geographically isolated locations, mainly on islands or settlements in developing countries, in areas of high ecological interest which must be protected and where there is abundance of renewable energy resources. Typically, they have a centralized topology, with radial networks and a few generation nodes that concentrate all the electrical power supply.

At present isolated electric systems largely depend on fossil fuels. New energy models pursue two main objectives: replacing conventional generation by renewable sources and improving overall system efficiency.

Because isolated power systems are not connected to the utility grid, they must be designed independently to meet the standards of reliability and quality of service. Moreover, because a high percentage of supply depends on renewable energy which is not controllable, it is necessary to establish new management protocols to ensure the safety and reliability of the electric system at all times. It follows that the technical requirements of the grid codes in isolated power systems are generally stricter than those for interconnected systems.

There are three main drawbacks associated with isolated electrical systems that highlight the need to develop specific grid codes. These disadvantages are shown in Figure 1:

Figure 1. Main drawbacks associated to isolated grids

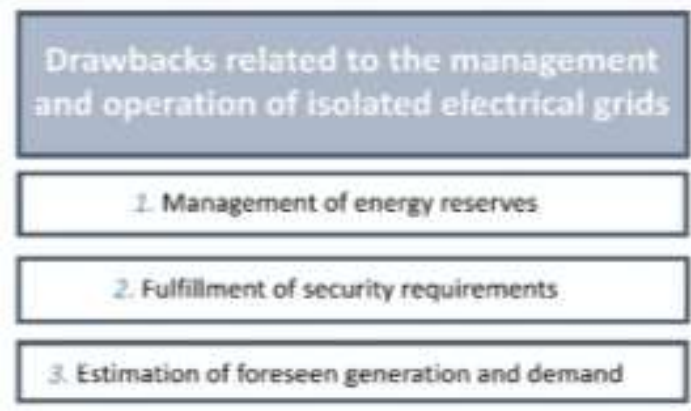

Management of energy reserves: management of isolated power systems is strongly influenced by the impact that contingencies have on the system operation, which is higher in the isolated systems compared to interconnected systems thereby forcing to set also greater levels of energy reserves. For this reason, conventional units work below their rated power, and thus lead to cost overruns. In reality this value is usually the minimum reserve allowed by the law of the country and, in many cases, is insufficient. Therefore, it is usual in these systems, before a severe failure, the system operator will restore normal operation of the grid through interruptible load shedding.

Fulfillment of security requirements: In isolated grids it is difficult to foresee any incidents that may occur because they have a high degree of uncertainty dependent on the variability of the voltage levels on the grid. Systems that have not yet implemented distributed generation (DG) have a risk inherent to the fact that are concentrated in a few nodes. They are also slightly meshed networks and with low 
voltage levels $(<66 \mathrm{kV})$. For the aforementioned reasons is common in these grids to have a high number of violations of $\mathrm{N}-1$ security criterion.

Estimation of foreseen generation and demand: The difficulty in forecasting horizons medium to long term in energy production from non-manageable generation or demand carries problems in estimating the ratio between conventional and renewable generation needed in the system to ensure stability.

\section{Characterization Of Voltage And Frequency Disturbances In Isolated Power Systems}

- Voltage dip:

The contingency that mostly affects the power quality in the electrical system is the voltage sag to such an extent that it represents almost $80 \%$ of short-term disturbances that occur in the grid [2]. A voltage dip is, as defined in [3], a sharp decrease in the voltage at an interconnection point followed by subsequent restoration and whose duration is comprised from $10 \mathrm{~ms}$ to $1 \mathrm{~min}$.

The causes of voltage dip are related to the connection or disconnection of elements in the system, either for operational reasons or because of short circuits. Usually in isolated power systems, nodes are physically close together, connected through very short distribution lines and are electrically equivalent points. The relative potency of the groups of generation/load with respect to the total power of the system is also important. These circumstances determine the characteristics that usually present voltage dips that take place in isolated power systems: they are very deep and their area of propagation is very wide-spread.

Fig. 2.a) shows the temporal profile of a voltage dip characteristic of those produced in the distribution network of $20 \mathrm{kV}$ of an isolated system as it is on the island of El Hierro [4] in the Canary Islands, which has an installed capacity of $11.5 \mathrm{MW}$ [5]. It is noted that the voltage at various close nodes of the network is practically the same as it is in a small grid. Moreover, in Fig. 2.b) it is shown how is the spread of a voltage dip in the electrical system of another Canary island, in this case, Gran Canaria, much larger (1120 MW) [5]. A short circuit at the output of the power station from $66 \mathrm{kV}$ affects the entire network and any node is capable of staying within permissible limits of voltage to the system.

\section{- Voltage swell/Overvoltage/Undervoltage}

Figure 2. (a) Characteristic voltage dip in El Hierro Island. (b) Spread of a voltage dip in Gran Canaria Island. 


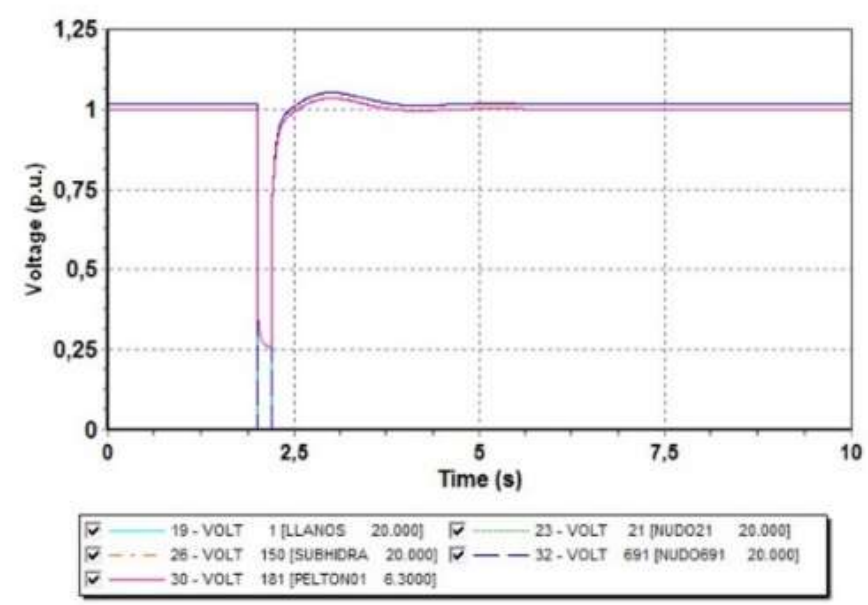

a)

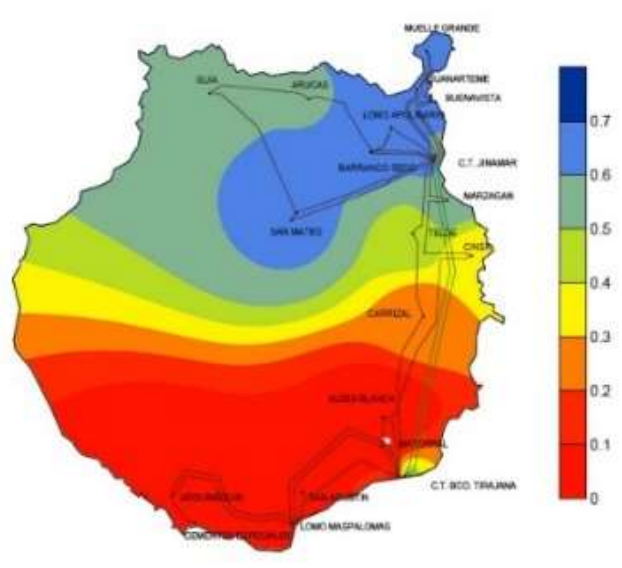

b)

In the isolated electrical systems fluctuations in voltage due to decreased voltage drops in the line. In this type of grid, lines offer a great impedance that causes a high dependence on the degree of load voltage drop, which seriously affects the power quality in the point of common coupling (PCC).

\section{- Frequency oscillations}

In any electrical system, frequency oscillations appear as a consequence of the imbalances between generation and load. The equation of oscillation of the electrical machines expressed in per unit (p.u.) over the potency base of the system is shown in (1):

$$
P_{m}-P_{e}=2 \cdot H \cdot \frac{d \omega}{d t}
$$

where $\mathrm{Pm}$ and $\mathrm{Pe}$ are respectively the total power of generation and loads in the system, in $\mathrm{pu}, \mathrm{H}$ is the sum of the inertias of the synchronous generating groups in seconds and $\mathrm{w}$ is the speed of the machines, in p.u. From the equation (1) it follows that the change in the rotational speed of the generators, and therefore the frequency of the network, is directly proportional to the instantaneous imbalance of generation and demand and inversely proportional to the sum of the inertias provided by the generating groups. In isolated low inertia diesel generators can usually be found, which in the event of disturbance leads to frequency excursions greater than those that would occur in an interconnected system.

\section{Current status of isolated power systems}

Many of the systems that were remote - and isolated- have been connecting progressively to other networks with similar characteristics or the Mainland due to the development of underwater interconnections using HVDC/HVAC links. Isolated networks which are connected to others and such that the set remains as isolated system, with its associated problems, include the case of the main islands of the Hawaiian Islands and North and South of New Zealand or Lanzarote and Fuerteventura Islands. In this sense an interconnection is also projected between the islands of Guadeloupe, Martinique and Dominica [6]. Other times, the joints are between islands and through them, to the 
Mainland as it is now being developed for the connection of the Italian Islands (Insula Project) [7] to continental Italy or has been carried out to link Sri Lanka to India [8]. Concerning the connection of remote grids to continental territories it should be mentioned that two projects are currently being defined by size and the technological challenge presented. The first of these is the EuroAsia Interconnector Project, which is developing a link of almost $1000 \mathrm{~km}$ long, with a capacity of 2000 MW, which will join the grids in Cyprus and Crete to the continental network of Greece and Israel and whose entry into service is scheduled for 2016 [9]. The second project, even before beginning, will allow a connection between Iceland and the United Kingdom [10]. Iceland has a very important geothermal, hydraulic and wind potential, so it is able to generate nearly five times the energy it consumes at a very low price. Importing cheap energy from Iceland to the United Kingdom on the other hand will create an economic advantage and therefore it will not have to expand its offshore wind generation capacity.

For other electrical outlying systems it is not possible to plan its interconnection due to the high cost which presupposes the construction of the linkage (not acceptable for example for the remote grids in developing countries) or due to the geographical situation. This happens in the Canary Islands: the distance between islands and the Mainland and especially the depth of the ocean floor do not make the connection viable. As future though unlikely solutions, HVAC links may be used to establish possible inter-island connections through offshore wind farms [11]. Therefore it is in these isolated electrical systems without possibility of later connection to the utility grid that the need to develop new specific codes to carry out the change of energy model towards the integration of clean energies takes on special importance.

\section{Overview of grid codes}

The grid codes are essentially sets of rules governing the connection and behavior that must satisfy coupled generators in power systems. The rules are different in each country and the corresponding operator is responsible for establishing those conditions and verification of compliance. The grid codes take as reference the electrical characteristics and the network design and their degree of demand is directly linked to the unmanageable power present and expected penetration rate.

There is a close relationship between regulations, the consequences that these establish for manufacturers and non disposable energy penetration rate in the system. The graphical summary of this idea can be seen in Figure 3: 
Figure 3. Relationship between grid codes and renewable energy development

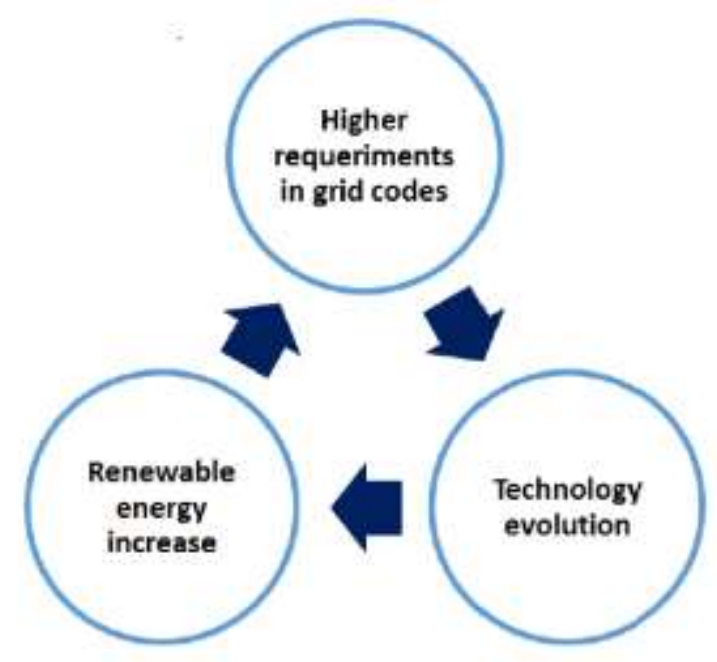

In each country, the regulatory framework is itself complex and changing, forcing manufacturers to adapt their products according to the market for which they are oriented. Although the requirements of the grid codes can be differentiated according to the type of technology that are applicable, the installation or the voltage level of generation, all regulations are structured in a similar way, gathering on the one hand the rules that collect connection requirements for collecting all those other aspects related to the operation and safety criteria (known by the generic name of Operating Procedures) and on the other hand the rules related to the electricity market [12]. In regard to the interest of this work, the comparison between different network codes isolated systems will be linked to issues addressed in the connection requirements and/or Operating Procedures such as voltage and frequency disturbances. Conditions of low voltage ride-through (LVRT) in any grid code are collected in the form of profiles, which report the permissible voltage levels and associated duration times. These profiles can be of two types:

1. Rectangular profiles established based on the steps of protections tripping.

2. Profiles with recovery in ramp: represent the most severe profiles obtained by statistical analysis of network failures.

The performance criteria to other disturbances through different voltage and included in the IEEE Std 1159-1995 [13] such as overvoltages, undervoltages or voltage swells are always determined by protections tripping times. Apart from the requirements in voltage, both conventional and renewable generation sources must be able to stay connected and in operation if the electrical system is subject to fluctuations in a permanent or transient regime. Likewise, in some regulations, additional obligations appear to make sources capable of supporting derivatives of frequency over a period of time (Rate of Change of Frequency -ROCOF) that can appear as a result of very abrupt changes in power-demand balance. 


\section{Grid codes in isolated systems}

Current regulations on grid codes applied to isolated power systems are scattered and incomplete. This is due either to small-sized electrical systems and sometimes developing countries do not have specific regulations or the small number of installed renewable generation sources do not justify the creation of a law regulating its integration in the electrical system. In the technical literature review examples of regulations have been found for large isolated electrical systems (> $50 \mathrm{MW}$ ). Only three have been specifically developed for medium or small ones $(<50 \mathrm{MW})$.

The first one is located in Spain, where the smallest island of the Canary Islands, El Hierro, has an installed capacity of only 11.5 MW. The Canary Islands are currently electrical systems pioneers in terms of bulk inclusion of renewable energy. Spanish law forced to take the specificity of Canarian systems into account. Therefore, the operating procedures established by the Spanish system operator (REE), includes a profile of specific dip for the Canary Islands which is different from the Peninsular territory or in other Spanish isolated power systems such as Baleares, Ceuta or Melilla [14]. The second case corresponds to France, which has several islands with installed powers between 27 MW and 435 MW - St Pierre et Miquelon, Guadeloupe, Martinique, Reunion and Corsica, - [15]. And the IEEE Std. 1547 constitutes the third case. The IEEE Std. 1547 applies to up to $10 \mathrm{MW}$ distributed generation sources connected to microgrids. In the strict sense, a unique source of that size and associated controls and protections would form a microgrid. And if this microgrid works in isolated mode without the possibility of subsequent connection to a bigger grid (which are known as remote microgrids) would also be an isolated electrical system itself. In the isolated power systems the maintenance of a high proportion of backup conventional generation is essential for safety. Therefore, French law establishes that the system operator can order disconnection of renewable generation sources when it reaches a level greater than 30\% instant penetration [16]. In Spanish code there is no imposed limitation in this respect and the disconnection depends on the particular legislation established for each island. By the year 2015 it is expected that in the Canary Islands a wind power penetration rate in both peak and valley will in many cases exceed 100\% [5]. This will force, or, to the search of efficient solutions of storage or to important spills of wind energy what supposes also that the massive integration of renewable energies in these islands is a challenge of that there is no well-known previous experience.

- $\quad$ oltage dip

Fig. 4. shows the most representative profiles of voltage dip for isolated power systems. Fig. 4 (a) collects profiles applicable to electrical systems of less than $50 \mathrm{MW}$ and Fig. 4. b) those which are over $50 \mathrm{MW}$. 
Figure 4. (a) Voltage dip profiles for systems up to $50 \mathrm{MW}$ (b) Voltage dip profiles for systems greater than $50 \mathrm{MW}$.
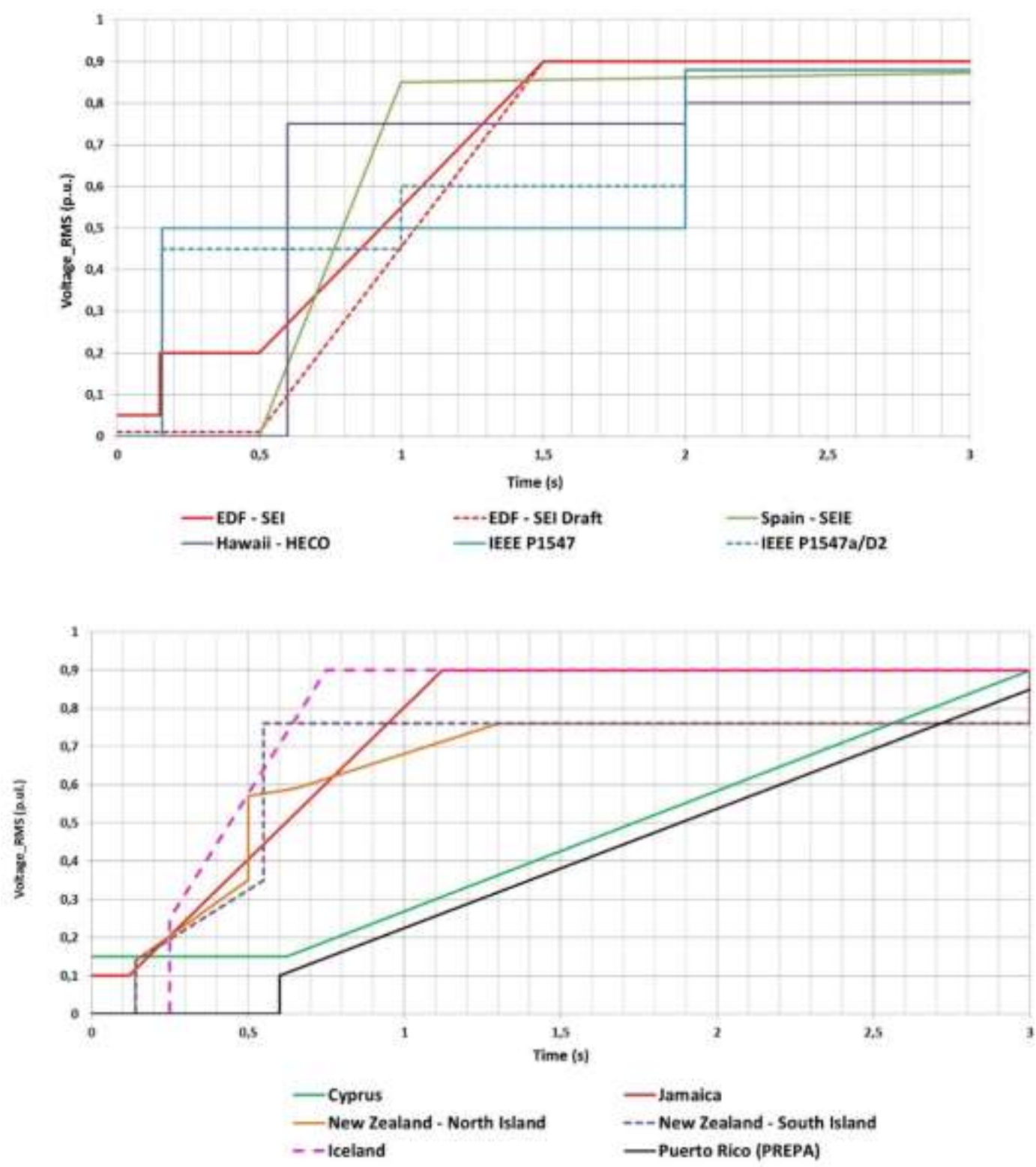

In conclusion, voltage dip profiles are demanding when the size of the grid is smaller, and virtually all profiles defined for isolated power systems include the requirement to withstand a voltage dip to zero, zero voltage ride through -ZVRT-, as is to be expected given the characteristics of the systems outlined in the introduction. In constrast, interconnected electrical systems are only enforceable requirements of thrusting voltage ride-through to zero in those systems that have a higher proportion of wind power installed, such as US (NERC), Germany or Spain in its new and not yet approved operation procedure, [17]. In the code EDF-SEI currently in service, the required voltage dip depth is 0.05 p.u [18]. To allow the increase of renewable energy in the French islands, a modification of this profile for a future policy with a required voltage dip depth of 0.01 p.u [19]. The forthcoming adoption of a new profile is also expected in an amendment to the regulations currently in service IEEE P1547 (IEEE P1547a/D2). 
- Overvoltage/Undervoltage

Figure 5. Overvoltage/Undervoltage requirements comparison for main isolated grid codes

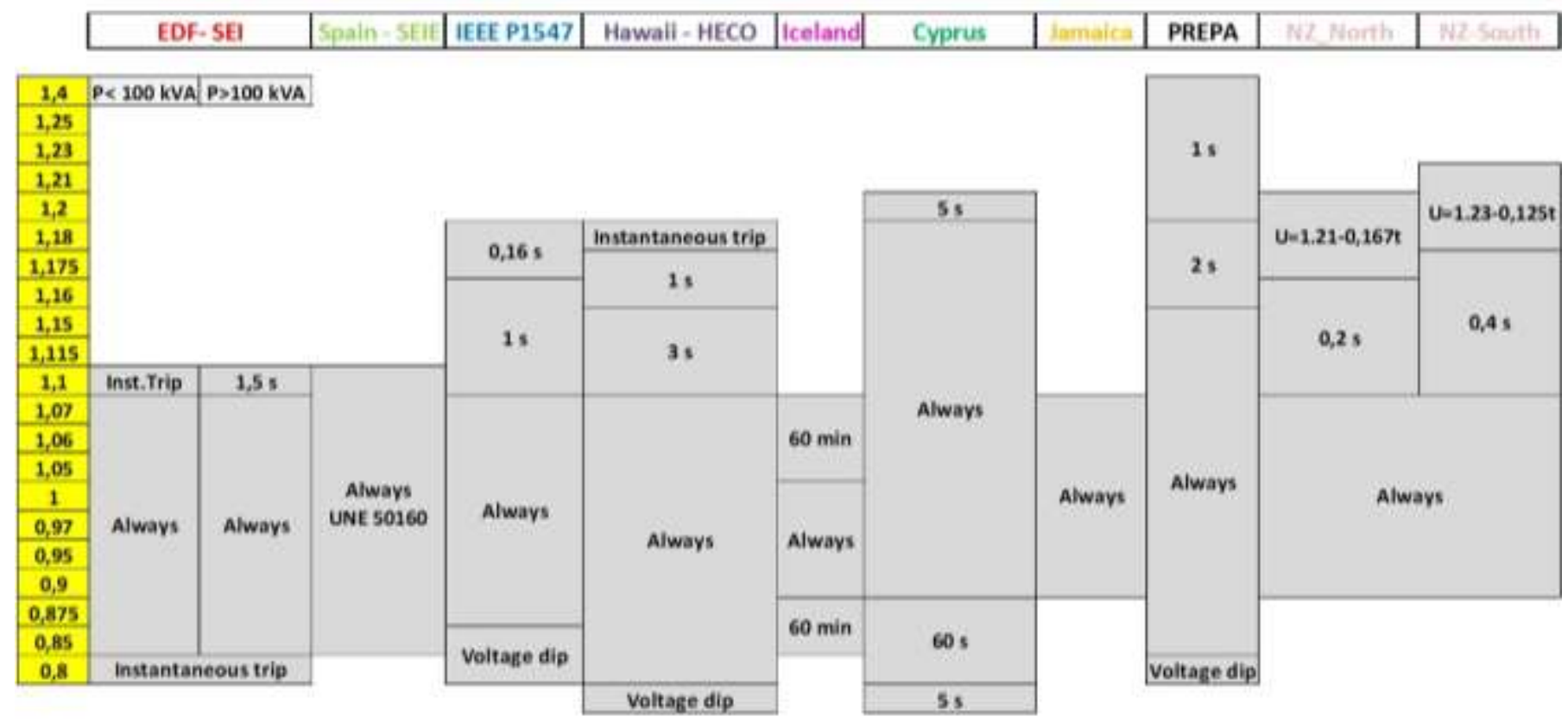

The ranges of operation in over/under voltage regime applied in isolated systems collectet in Fig. 5 , are stricter regarding required variations with respect to the ones observed in interconnected systems., The widest operating boundaries for interconnected systems are required in the new draft procedure of Spain - Draft P.O.12.2 - in which the generator should remain connected for 30 min with a voltage of 0.85 p.u. and $50 \mathrm{~ms}$ if the voltage remains at 1.20 p.u. By way of comparison, specifically in the case of an undervoltage event (0.85 p.u) occurs in isolated grid codes as EDF-SEI, Spain SEIE, HAWAII-HECO or Puerto Rico-PREPA [20] generators may not be never disconnected.

\section{- Frequency oscillations}

Fig. 6 shows a collection of the demanded frequency requirements in different network codes isolated systems. It is observed that in some cases, frequency fluctuations that systems must withstand continuously are very important. Note for example the case of the South Island of New Zealand, where the steady state frequency can fluctuate up to $8 \mathrm{~Hz}$. These levels would be completely unacceptable to any interconnected system. 
Figure 6. Frequency requirements in main isolated grid codes

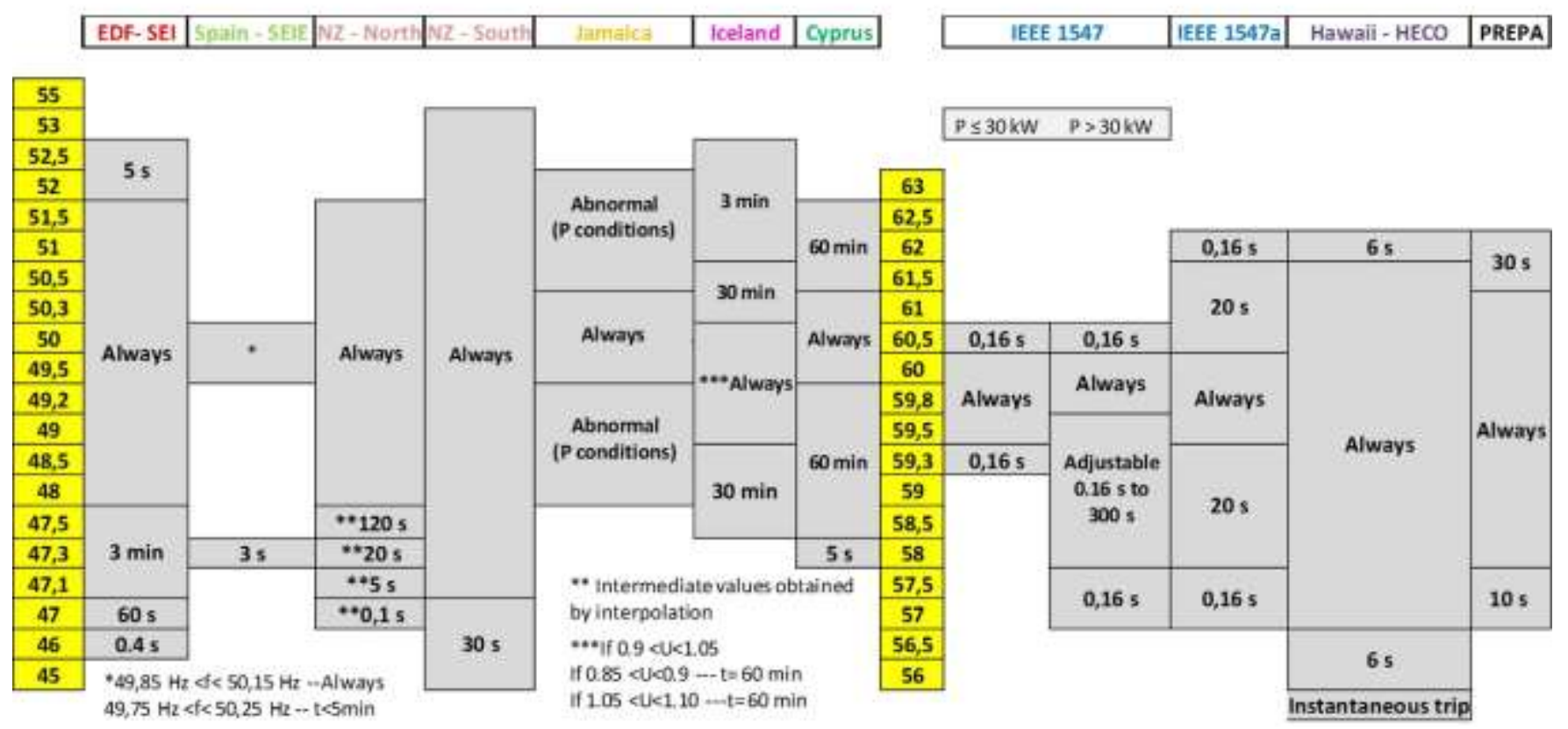

- Derivatives of frequency

The requirement that generation sources remain connected to derived frequency is not common to all network codes analyzed, but is reflected in some of them. For example in Hawaii, generators must remain connected to variations of up to $0.37 \mathrm{~Hz}$, in New Zealand, $0.75 \mathrm{~Hz} / \mathrm{s}$ and in Cyprus up to 1.3 $\mathrm{Hz} / \mathrm{s}$.

\section{Future trends in isolated grid codes}

Depending on the legislation of the country in which it is applied, manufacturers may be required to certify their equipment according to each of the grid codes of territories that sell and install their products. In addition, the creation of a common grid code will allow increasing levels of security and stability in the network and facilitate the inclusion of new sources of renewable generation in the system. That is why the need to harmonize the different regulations increasingly appears more strongly. Europe have made great strides in this regard, by means of the ENTSO-E organization. This organization brings together the technical operators of the European electrical systems and is responsible for both coordination between different TSOs to control energy exchanges between European countries borders, in collaboration with the Agency for the Cooperation of the Energy Eegulators (ACER) and the operators of the electricity market. The ENTSO-E organization has many years of experience in the development of joint legislation ensuring minimum requirements that must be specified in all the member states, unified terminology and set of compliance obligations and exceptions equally applied to all European countries. From the perspective of what is an isolated system as defined in the introduction are various European territories that meet these characteristics, such as the Canary Islands, Cyprus, Malta, Madeira or the Åland Islands. ENTSO-E code aims at the 
unification of the grid codes for the construction of a pan-European electrical system. The isolated power systems would presuppose a very small impact on the global system (if they could finally be connected to the Mainland) or no impact if kept isolated by geographical circumstances. In either case, the effects of electrical systems will be minimal and are excluded in this initial version of the European code ENTSO-E.

However the importance of finding agreement on the unification of the laws existing in the different territories has forced the creation of a group within the structure of ENTSO-E specializing in isolated systems: the Regional Voluntary Group Isolated Systems (VRG IS). This is a group consisting of four large European operators: electrical network of Spain (Spain), Terna (Italy), Landsnet (Iceland) and Cyprus Transmission System Operator (Cyprus). Its mission will be to ensure the proper management and operation of the isolated power systems and provide its expertise so that in the development and updating of the grid codes, the particularities of isolated power systems are taken into account. The experience provided by the VRG IS presumably will be included in future publications of the code [21].

The increasing integration of sources of generation in the non-conventional networks suggests that the general idea that the legislation pursues is to ensure that the renewable generation sources embedded in the electrical systems react to shocks like conventional generators mostly in service, The regulation ensures that the replacement of some sources of generation by others does not pose additional risks for the electrical systems. This is necessary in every network but need will be more accused in weak grids. For this reason, the inclusion of several additional requirements is expected on those currently in service. The first version of the Spanish grid code P.O.12.2, published in 2008, cited some requirements and even the mode of implementation in the system. Spanish regulation is one of the most advanced and since Spanish operator REE is a member of the ENTSO-E, it is likely that the line marked by this draft code will be extended to future grid codes. These new requirements for nonconventional generation would be two:

- Emulation of inertia: It will require non-conventional generation sources, connected through a converter, to emulate the inertia provided by the rolling mass of conventional generators. Nonconventional sources should be able to increase or decrease the active power that they inject at the point of common connection according to frequency deviations.

- Capacity of damping frequency oscillations in the system: The system must be capable of providing active power that can compensate for the low-frequency oscillations in the system.

Apart from these two requirements, the first version of the 2008 Code expresses the desirability of control systems to evolve to provide reverse sequence during power disturbances.

\section{Conclusions}

There are difficulties in integrating intermittent energy in any electrical system. These difficulties grow if it is an isolated system. On the one hand, the replacement of conventional generation sources 
by renewable sources is especially required in isolated systems given that they currently have a high external energy dependency which increases the costs of electricity supply. On the other hand, the inability of the isolated systems to connect to the utility grid and the high relative size of the generating units/loads with respect to the total system power, magnify the problems linked to the stability and security of the network. Therefore, there is an increasing number of grid codes which are developed to facilitate the inclusion of non-conventional energy - especially wind energy- in isolated power systems. In them the requirements established by the operators are more demanding. There are many isolated systems which given its very small size or for being in developing countries lack specific codes. Moreover the legislation associated with the development and approval of new grid codes is constantly changing. This work compiles actual status of isolated power systems, showing the need of develop specific grid codes for them and collecting several examples of currently grid codes applied to weak grids.

\section{Acknowledgments}

This work has been funded by the Spanish Ministry of Economy and Competitiveness under FPI Programme research grant PN-ENE2009-13276.

\section{Conflicts of Interest}

The authors declare no conflict of interest.

\section{References and Notes}

1. Directive 2009/72/CE. European Parliament and The Council of European Union: 2009.

2. Electric Power Research Institute (EPRI). Voltage sags, swells and interruptions characterized in DPQ Phase II Project. 2005.

3. Ministerio de Industria, Turismo y Comercio. P.O.12.3 - Requisitos de respuesta frente a huecos de tensión de las instalaciones eólicas (in Spanish). Boletín Oficial del Estado 2006, 254.

4. Merino, J., Veganzones, C., Sanchez, J.A., Martinez, S., and Platero C.A. Power system stability of a small-sized isolated network supplied by J.A. a combined wind-pumped storage generation system: A case study in the Canary Islands. Energies 2012, 5, 2351-2369.

5. Rupérez, J. Red Eléctrica de España. Proyecto TRES. Integración de energías renovables en sistemas aislados y estabilidad. www.proyectotres.itccanarias.org (accessed on 222 2014).

6. Guadeloupe Energie. http://www.guadeloupe-energie.gp/wp-content/uploads/ /Plaquette_Geothermie_English.pdf (accessed on 162 2014).

7. TERNA. http://www.terna.it/LinkClick.aspx?fileticket=88244 (accessed on 222 2014).

8. Jowsick, A.J.M.I.; Arulampalam, A.; Wijekoon, H.M. HVDC transmission line for interconnecting power grids in India and Sri Lanka. In Fourth International Conference on Industrial and Information Systems (ICIIS), Sri Lanka, 28-31 December 2009.

9. EuroAsia Interconnector Project. http://www.euroasia-interconnector.com/ (accessed on 222 2014). 
10. Hammons, T.J.; Hreinsson, E.B.; Kacejko, P. Proposed Iceland/UK (Peterhead) 1.2 GW HVDC cable. In Universities Power Engineering Conference (UPEC), $201045^{\text {th }}$ International, Cardiff, Wales, 31 August - 3 September 2010.

11. Lobato, L. Potencial de la eólica marina. Importancia para el desarrollo de las conexiones submarinas. Jornadas de la Asociación Empresarial Eólica (AEE). Integración en Red: soluciones para altas penetraciones eólicas en sistemas insulares. Las Palmas de Gran Canaria, España, 8 - 9 November 2010. Available online: http://www.aeeolica.org/es/new/integracion-en-red-solucionespara-altas-penetraciones-eolicas-en-sistemas-insulares/

12. European Network of Transmission System Operators for Electricity (ENTSO-e). http://networkcodes.entsoe.eu/ (accessed on 22 2014).

13. IEEE Recommended Practice for Monitoring Electric Power Quality; IEEE Std 1159-1995, vol., no., pp.i, 1995.

14. Ministerio de Industria, Turismo y Comercio. P.O.12.2 - SEIE: Instalaciones conectadas a la red de transporte de energía eléctrica. Requisitos mínimos de diseño, equipamiento, funcionamiento y seguridad y puesta en servicio (in Spanish). Boletín Oficial del Estado 2006, 129, 143.

15. U.S. Energy Information Administration. http://www.eia.gov (accessed on 222 2014).

16. EDF. Référentiel technique de raccordment des installations de production d'électricité aux reseaux HTA et BT des zones non interconnectées. SEI REF 02. V4 (in French). 2006. Available online: http://www.edf.com/fichiers/fckeditor/Commun/SEI/corp/SEI_REF_02_v4.pdf (accessed on 222 2014).

17. Asociación Empresarial Eólica (AEE). Requisitos técnicos de las instalaciones eólicas, fotovoltaicas y todas aquellas instalaciones de producción cuya tecnología no emplee un generador síncrono conectado directamente a la red. Separata del borrador de P.O.12.2. Instalaciones conectadas a la red de transporte y equipo generador: requisitos mínimos de diseño, equipamiento, funcionamiento, puesta en servicio y seguridad (in Spanish). October 2008. Available online: http://www.aeeolica.org/uploads/documents/4535-separata-del-borrador-de-po122.pdf.

18. EDF. Protection de découplage pour le raccordement d'une production décentralisée en HTA et en BT dans les zones non interconnectées. SEI REF 04 (in French). Available online: http://saint-pierre-et-miquelon.edf.com/fichiers/fckeditor/Commun/SEI/corp/ sei_ref_04_protection_decouplagev5.pdf

19. EDF. How to manage intermittency on islands? 7 November 2012. Available online: http://chercheurs.edf.com/fichiers/fckeditor/Commun/R_et_D/7nov_EnR_Intermittence/Presentati ons_7nov12/10_Barlier_EDF_SEI.pdf (accessed on 222 2014).

20. Vahan, G. and Booth, S. National Renewable Energy Laboratory (NREL). Review of PREPA Technical Requirements for Interconnecting Solar and Wind Generation. November 2013.

21. European Network of Transmission System Operators for Electricity (ENTSO-e). Voluntary Regional Group Isolated Systems. https://www.entsoe.eu/about-entso-e/systemoperations/regional-groups/vrg-isolated-systems/ (accessed on 222 2014). 
(C) 2014 by the authors; licensee MDPI, Basel, Switzerland. This article is an open access article distributed under the terms and conditions of the Creative Commons Attribution license (http://creativecommons.org/licenses/by/3.0/). 